\title{
Wind Farm Grid Integration Architecture using Unified Expandable Power Converter
}

\author{
Hamed Bizhani, Student Member, IEEE, Reza Noroozian*, Member, IEEE, S. M. Muyeen, Senior, \\ IEEE, Frede Blaabjerg, Fellow, IEEE.
}

\begin{abstract}
This paper proposes a novel unified expandable low switch power electronic converter architecture for grid integration of direct drive variable speed wind turbine (VSWT) system using permanent magnet synchronous generator (PMSG). The proposed unified expandable power converter (UEPC) can interface two or more bidirectional output ports such as wind generators, energy storages and grid. The size of the power converter is compact because of low number of power electronic switches and protection devices and its architecture is easily expandable to accommodate more outputs, i.e., in this case, the wind turbines. A generalized sequential space vector modulation technique is developed based on the operational principle of the proposed converter to control of the outputs autonomously in order to track maximum power point for individual VSWTSs driven PMSG's. It is expected that the proposed approach will reduce the cost of power electronic converters in a wind farm compared to both AC- and DC-link based topologies, which are available for the moment.
\end{abstract}

Index Terms- Autonomous control, grid integration, maximum power point tracking, permanent magnet synchronous generator, sequential space vector modulation, unified expandable power converter, wind turbine.

\section{INTRODUCTION}

G IVEN the increased cost of conventional power generation, environmental concerns, and reducing the cost of renewable technologies, some technological advancements have already been made in the renewable sector in recent years [1]-[4]. The wind turbine system is one of these renewable energy sources, which has experienced capacity increase from a few tens of $\mathrm{kW}$ to multi-MW power production unit [5]. Wind turbines are generally divided into two categories according to the rotational speed of rotor (1) the fixed speed turbines - the old trend [6], and (2) the variable speed wind turbines - which is the present trend [7]. The commercially available variable speed turbines use permanent magnet synchronous generators (PMSGs) [8]-[10], and doubly fed induction generators (DFIGs) [11]-[13], though the former type is becoming more popular nowadays. The power electronic

Manuscript received on March 23,2018; revised on May 15,2018; accepted on June 29, 2018.

H. Bizhani is with the Department of Electrical Engineering, Faculty of Engineering, University of Zanjan, University Blvd, Zanjan 45371-38791, I. R. Iran, and also with Electrical and Computing Department, Curtin University, Perth, WA $6102 \quad$ (e-mail: hamedbizhani@znu.ac.ir, hamed.bizhani@curtin.edu.au). interface is an essential part for integrating the variable-speed wind power generation unit to increase efficiency and improve performance [14].

In recent years, various converters have been introduced for use on VSWT driven PMSG. These converters can be divided into three categories: a) Multi-level converters [15]-[18], b) Special converters [19-21], and c) Multi-port converters [22][26]. In [15], a three-phase parallel grid-tied multi-level converter including a second- to tenth-free harmonics pulse width and height modulation (PWHM) switching scheme is presented. That converter can connect renewable energy sources (RES) to the power grid solving power quality issues as well as reducing the device count. A hybrid modular multi-level converter for interfacing a VSWTS-PMSG is proposed in [16], which is used at the grid side of the system and consists of a three-level modular multilevel converter (MMC) in series connection with three H-bridge modules. In [17], two direct model predictive control (DMPC) with hexagon candidate region (HCR) and triangle candidate region (TCR) for torque and power control of three-level neutral-point clamped (NPC) back-to-back converters are proposed. By a proper use of the candidate regions, the number of acceptable switching states is lowered significantly that reduces the computational time up to $55 \%$ and $83 \%$ for HCR and TCR methods, respectively. The current distortions induced by various open-switch faults in a back-to-back converter using the NPC topology have been reported in [18]. In [19], a special power-conditioning unit (PCU) for micro VSWTS-PMSGs is presented. The PCU contains of a simple generator-side rectifier, galvanic isolation with a simple dc-dc converter, and a single-phase full-bridge inverter at the grid side. The proposed dc-dc converter allows reducing the complexity of the PCU, however, the converter suffers from the number of power conversion stages and also the inability of tracking the maximum power point for the PMSG. In [20], the generator side converter in VSWTSPMSGs has been replaced with a Vienna rectifier. By considering the effects of Vienna rectifier voltage on the PMSG's torque and flux, direct torque control of the PMSG is presented. A medium frequency link isolation transformer

*Corresponding author: R. Noroozian is with the Department of Electrical Engineering, Faculty of Engineering, University of Zanjan, University Blvd, Zanjan 45371-38791, I. R. Iran, (e-mail: noroozian @ znu.ac.ir)

S. M. Muyeen is with the Electrical and Computer Engineering Department, Curtin University, Perth, WA 6102 Australia, and also with Centre of Smart Grid and Sustainable Power Systems, Curtin University, Perth, WA 6102 Australia (s.m.muyeen@ieee.org).

F. Blaabjerg is with the Department of Energy Technology, Aalborg University, Aalborg 9220, Denmark (e-mail: fbl@et.aau.dk). 


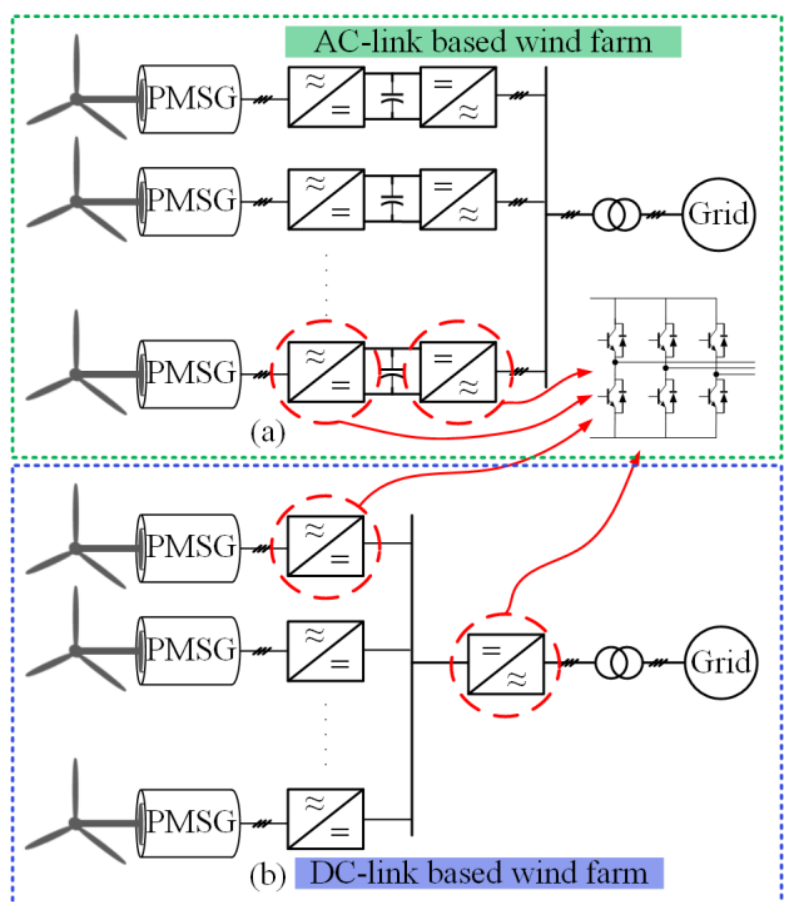

Fig. 1. Conventional converter topologies for VSWTS-PMSG in (a) AC-link based and (b) DC-link based wind farm.

based interface converter for grid integration of a wind turbine generator and battery energy storage system (BESS) has been reported in [21] and in [22] where a three switches leg based multi-input converter is proposed. In this topology, the number of inputs is increased without using multi-input transformers. A three-phase six-switch dual input converter is developed and employed as a rectifier to integrate two VSWTS-PMSG into the utility grid in [23]. In [24], a VSWTS-PMSG and a three-phase PWM-based three-leg AC/AC converter as power electronic interface between PMSG and network is proposed. A dualinput nine-switch converter as a front-end interface of two independent VSWTS-PMSG and a multi-channel dual configuration based on nine-switch converters for its use with multi-phase PMSG are reported in [25]-[26], respectively.

The review of the used power electronic interfaces for integration of VSWT-PMSG shows that researchers have not investigated the use of unified converters with reduced number of switches for integration of multiple wind turbines in a wind farm. For this purpose, a compact low switch Unified Expandable Power Converter (UEPC) for the integration of AC distribution generation is proposed in this paper. The general structure of proposed converter is presented and compared with the existing converter topologies used in a wind farm. Then, a sequential space vector modulation (SSVM) technique is developed for independent control of all outputs. The mathematical expression for the DC-link voltage requirement for the proposed converter is also established. Finally, in order to verify the proposed structure, this UEPC is used to integrate the two VSWT driven PMSGs that connects the power grid. The autonomous controllers are designed to track PMSGs' maximum power point, the DC-link voltage of UEPC, and unity power factor at the grid side.

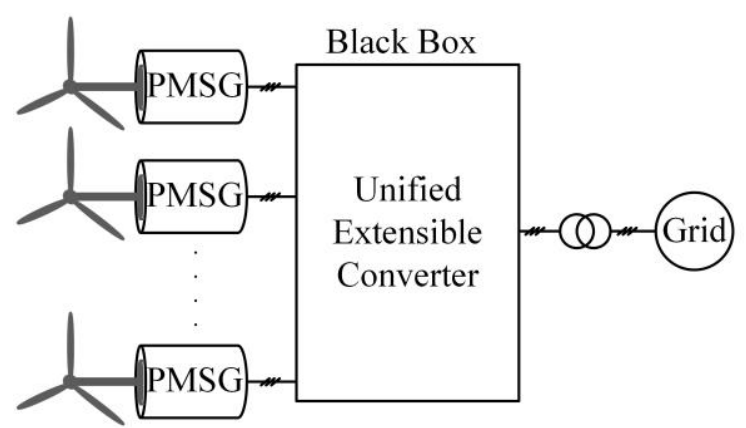

(a)

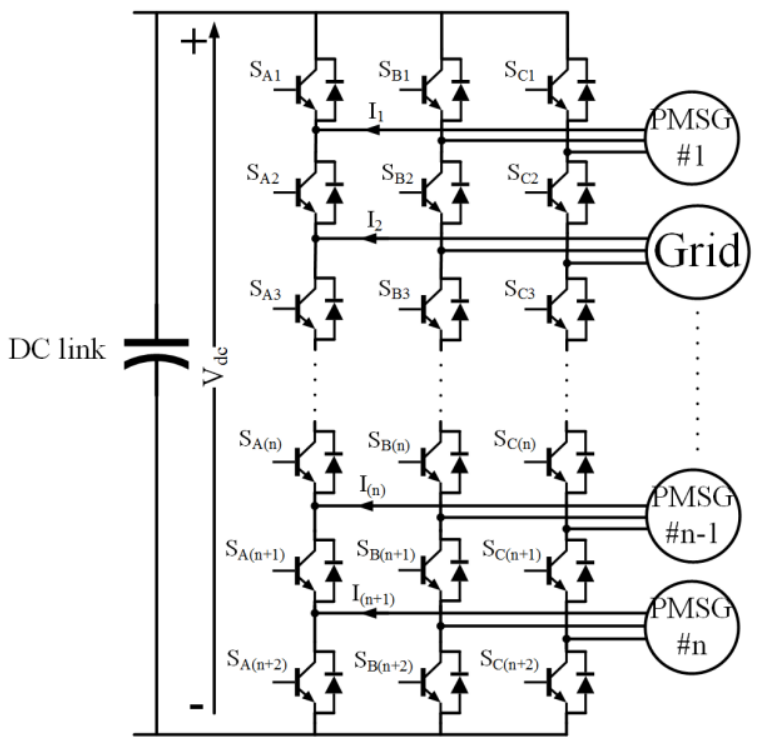

(b)

Fig. 2. Proposed UEPC topology (a) black box structure (b) generalized switching architecture including grid connection.

TABLE I

COMPARISON OF CONVENTIONAL TOPOLOGIES WITH THE PROPOSED UEPC

\begin{tabular}{|c|c|c|c|}
\hline & \multicolumn{3}{|c|}{ No. of switches in different topologies } \\
\hline No. of PMSGs & AC-link based & DC-link based & Proposed \\
\hline 1 & 12 & 12 & 9 \\
\hline 2 & 24 & 18 & 12 \\
\hline$:$ & $:$ & $:$ & $:$ \\
\hline$n$ & $12 n$ & $6(n+1)$ & $3(n+2)$ \\
\hline
\end{tabular}

\section{Proposed Power Converter Architecture}

There are two kinds of conventional power converter topologies available today for integration of the VSWTSPMSG in a wind farm as shown in Fig. 1 [27]. In the first one, as shown in Fig. 1(a), each VSWTS-PMSG is connected to the AC link through its own individual generator side converter and the grid side inverter. The total generated power by PMSGs goes to the AC link and then transfers to the grid through a stepup transformer. In the later one, the AC link has been replaced with a DC-link. In other words, each PMSG has its own generator side converter and injects the generated power to the DC-link. Then the total generated power is injected to the grid through the use of a grid side inverter as shown in Fig. 1(b). To 


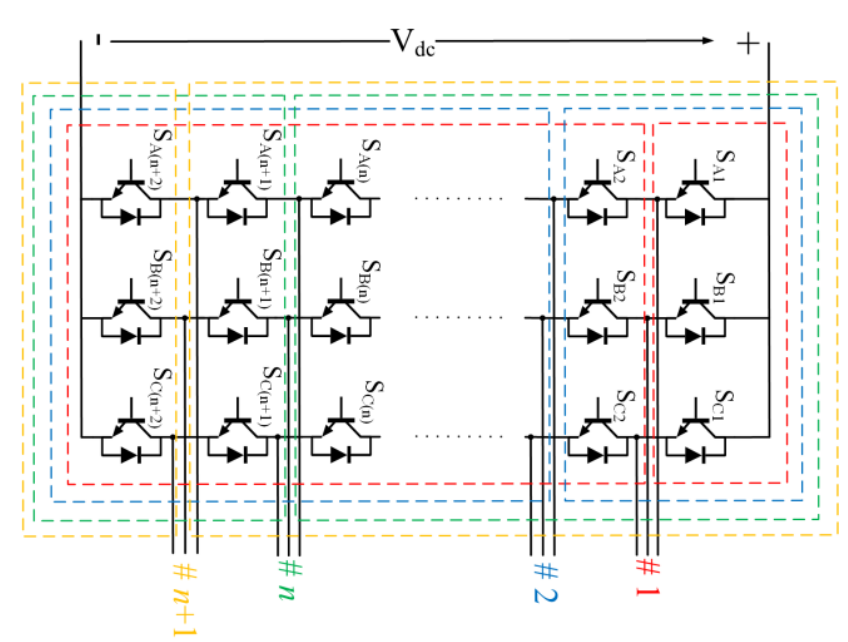

Fig. 3. Common switches for different outputs of the system in Fig. 2.

reduce the number of switches, as shown in Fig. 2, this paper presents an UEPC that can be replaced in both conventional structures of a wind farm. In comparison with existing topologies, the UEPC is compact, which means that all converters can be unified into one converter. Table I shows that for integration of $n$ number of VSWTS-PMSGs, the UEPC has $3(3 n-2)$ and $(3 n)$ less switches compared to the conventional $\mathrm{AC}$ and DC-link based converter topologies. In addition, the UEPC requires only one digital signal processor (DSP) for SSVM implementation. The requirements for the number of ports in DSP is less in the proposed UEPC as it requires less number of switches. Furthermore, in comparison to some recently invented low switched converters applied to VSWTSPMSG for grid integration, the proposed UEPC has unique and superior characteristics as given below:

- The UEPC can be considered as a black box power electronic interface in which $\mathrm{AC}$ sources can be connected to all AC output ports. In other words, each output port can be used as a grid or PMSG connection. However, in the proposed converters in [23] and [25], the grid and PMSGs connection have their individual ports.

- As the proposed converter is unified, it requires only one DSP although the converters in [23], [25] and [26] require two DSPs as the minimum.

- Regardless of the number of integrated PMSGs, only one DC-link capacitor is required in UEPC, whereas $n+1$ capacitors are required for the integration of $n$ number of PMSGs using the converter reported in [23].

\section{A. Operation Principle of UEPC}

As it is shown in Fig. 3, in the proposed converter all switches are active switches for different outputs, which means for the power flow between DC-link and each output, all switches are used. Therefore, at first glance it seems the autonomous control of the outputs is impossible. Nevertheless, by using an accurate switching method for UEPC, as discussed in next section, the autonomous control of outputs can be achieved. As a result, the maximum power point tracking for individual PMSGs is achievable and it is a salient feature of this work. Regardless of which output uses for connecting to the grid, the grid should also control the DC-link voltage and power
TABLE II

ON AND OFF STATES OF EACH LEG SWITCHES Given IN FIG. 3

\begin{tabular}{cccccccccc}
\hline & $\mathbf{S}_{\mathbf{J} 1}$ & $\mathbf{S}_{\mathbf{J} 2}$ & $\mathbf{S}_{\mathbf{J} 3}$ & $\ldots$ & $\mathbf{S}_{\mathbf{J}(\mathbf{K})}$ & $\ldots$ & $\mathbf{S}_{\mathbf{J}(\mathbf{n})}$ & $\mathbf{S}_{\mathbf{J}(\mathbf{n}+\mathbf{1})}$ & $\mathbf{S}_{\mathbf{J}(\mathbf{n}+\mathbf{2})}$ \\
\hline $\mathbf{1}$ & OFF & ON & ON & $\ldots$ & ON & $\ldots$ & ON & ON & ON \\
\hline $\mathbf{2}$ & ON & OFF & ON & $\ldots$ & ON & $\ldots$ & ON & ON & ON \\
\hline $\mathbf{3}$ & ON & ON & OFF & $\ldots$ & ON & $\ldots$ & ON & ON & ON \\
\hline$:$ & $:$ & $:$ & $:$ & $\ldots$ & $:$ & $\ldots$ & $:$ & $:$ & $:$ \\
\hline $\mathbf{K}$ & ON & ON & ON & $\ldots$ & OFF & $\ldots$ & ON & ON & ON \\
\hline$:$ & $:$ & $:$ & $:$ & $\ldots$ & $:$ & $\ldots$ & $:$ & $:$ & $:$ \\
\hline $\mathbf{n}$ & ON & ON & ON & $\ldots$ & ON & $\ldots$ & OFF & ON & ON \\
\hline $\mathbf{n + 1}$ & ON & ON & ON & $\ldots$ & ON & $\ldots$ & ON & OFF & ON \\
\hline $\mathbf{n + 2}$ & ON & ON & ON & $\ldots$ & ON & $\ldots$ & ON & ON & OFF \\
\hline
\end{tabular}

TABLE III

INDIVIDUAL AND COMMON VECTORS OF VARIOUS OUTPUTS OF

UEPC

Generated vector

A

B

C

\begin{tabular}{|c|c|c|c|}
\hline \multicolumn{4}{|c|}{$\begin{array}{l}\text { Individual active vectors for } I^{\text {th }} \text { output and zero vectors for other } \\
\text { outputs where }(1 \leq I \leq n+1) \text { see Fig. } 4 \text { (a) }\end{array}$} \\
\hline (100) & $\mathrm{I}+1$ & I & I \\
\hline (110) & $\mathrm{I}+1$ & $\mathrm{I}+1$ & I \\
\hline$(010)$ & I & I+1 & I \\
\hline (011) & I & $\mathrm{I}+1$ & $\mathrm{I}+1$ \\
\hline (001) & I & I & $\mathrm{I}+1$ \\
\hline (101) & $\mathrm{I}+1$ & I & $\mathrm{I}+1$ \\
\hline \multicolumn{4}{|c|}{$\begin{array}{l}\text { Common and same active vectors for } I^{\text {th }} \text { and }(I+1)^{\text {th }} \text { outputs and } \\
\text { zero vectors for other outputs where }(1 \leq I \leq n) \text { see Fig. } 4 \text { (b) }\end{array}$} \\
\hline (100) & $\mathrm{I}+2$ & I & I \\
\hline (110) & $\mathrm{I}+2$ & $\mathrm{I}+2$ & I \\
\hline (010) & I & $\mathrm{I}+2$ & I \\
\hline (011) & I & $\mathrm{I}+2$ & $\mathrm{I}+2$ \\
\hline (001) & I & I & $\mathrm{I}+2$ \\
\hline (101) & $\mathrm{I}+2$ & I & $\mathrm{I}+2$ \\
\hline : & : & : & : \\
\hline
\end{tabular}

Common and same active vectors for $I^{\text {th }}$ to $(I+j-1)^{\text {th }}$ outputs and zero vectors for other outputs where $(1 \leq I \leq n+1) \&(1 \leq j \leq n+2-I)$ see Fig. 4(c)

\begin{tabular}{|c|c|c|c|}
\hline (100) & $\mathrm{I}+\mathrm{j}$ & I & I \\
\hline (110) & $\mathrm{I}+\mathrm{j}$ & $\mathrm{I}+\mathrm{j}$ & I \\
\hline (010) & I & $\mathrm{I}+\mathrm{j}$ & I \\
\hline (011) & I & $\mathrm{I}+\mathrm{j}$ & $\mathrm{I}+\mathrm{j}$ \\
\hline (001) & I & I & $\mathrm{I}+\mathrm{j}$ \\
\hline (101) & $\mathrm{I}+\mathrm{j}$ & I & $\mathrm{I}+\mathrm{j}$ \\
\hline \multicolumn{4}{|c|}{$\begin{array}{l}\text { Common and same active vectors for } I^{\text {th }} \text { to }(I+j-1)^{\text {th }} \text { outputs, } \\
\text { common and same active vectors for }(I+j)^{\text {th }} \text { to }(I+j+k-1)^{\text {th }} \text { and } \\
\text { zero vectors for other outputs where }(1 \leq I \leq n) \&(1 \leq j \leq n+1-I) \& \\
\qquad(1 \leq k \leq n+2-I-j) \text { see Fig. } 4(d)\end{array}$} \\
\hline (110) (100) & $\mathrm{I}+\mathrm{j}+\mathrm{k}$ & $\mathrm{I}+\mathrm{j}$ & I \\
\hline (101) (100) & $\mathrm{I}+\mathrm{j}+\mathrm{k}$ & I & $\mathrm{I}+\mathrm{j}$ \\
\hline (011) (010) & I & $\mathrm{I}+\mathrm{j}+\mathrm{k}$ & $\mathrm{I}+\mathrm{j}$ \\
\hline (011) (001) & I & $\mathrm{I}+\mathrm{j}$ & $\mathrm{I}+\mathrm{j}+\mathrm{k}$ \\
\hline (101) (001) & $\mathrm{I}+\mathrm{j}$ & I & $\mathrm{I}+\mathrm{j}+\mathrm{k}$ \\
\hline (110) (010) & $\mathrm{I}+\mathrm{j}$ & $\mathrm{I}+\mathrm{j}+\mathrm{k}$ & I \\
\hline \multicolumn{4}{|c|}{ Zero vectors for all outputs where $(1 \leq I \leq n+2)$ see Fig. $4(\mathrm{e})$} \\
\hline$(000)$ or $(111)$ & I & I & I \\
\hline
\end{tabular}

flow between the outputs, autonomously.

\section{B. Sequential Space Vector Modulation (SSVM) for UEPC}

The SSVM is used to independently control the AC outputs in the proposed converter. In the SSVM, the switching time is divided between the outputs based on the modulation index of each output [28]. In each subinterval, the active vectors of the related output are applied. These active vectors for each output will be zero vectors for other outputs at the same time. For the integration of $n$ number of PMSGs, $n+1$ outputs and $n+2$ switches in each leg are required. As in each leg at least $n+1$ switches must be ON, the status of switches can be as 

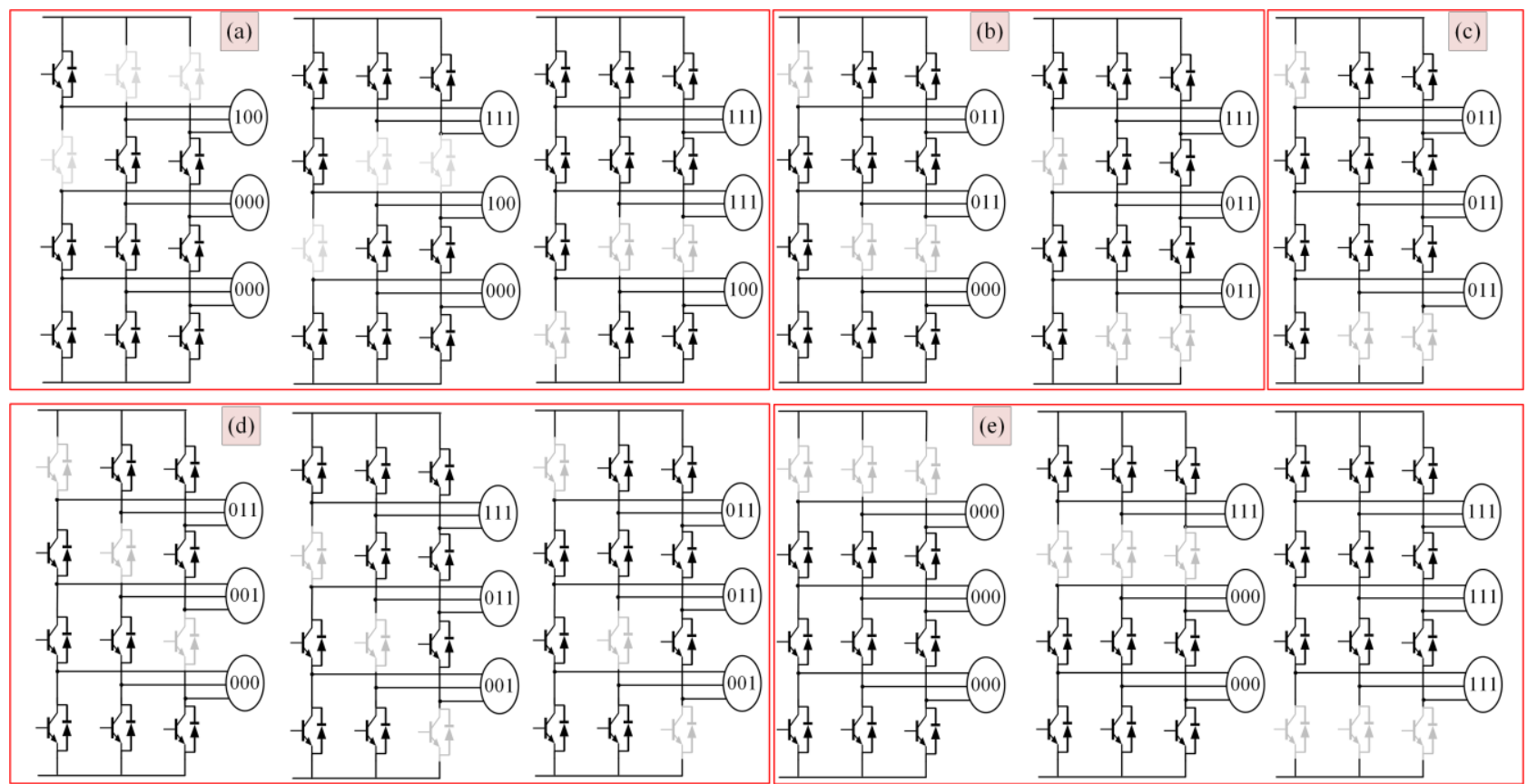

Fig. 4. Selective operation modes and current flow for three outputs converter.

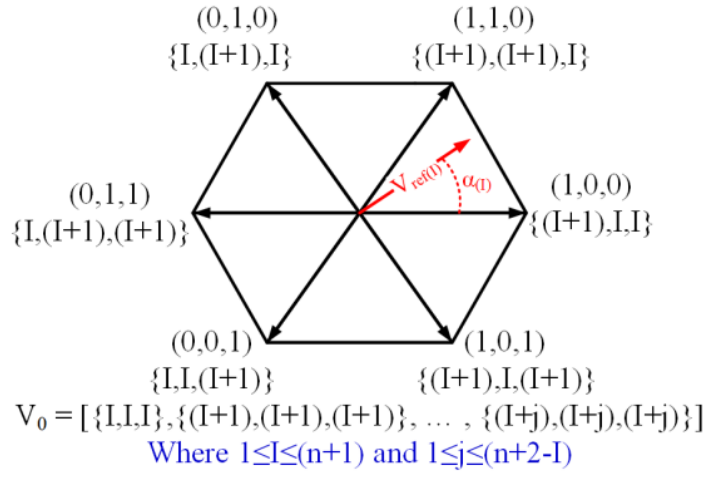

Fig. 5. Space vector diagram of the I-th output in the converter where $V_{\text {reffI }}$ is the reference voltage vector.

summarized in Table II, where $\mathrm{J}$ means A, B and C legs of the $\mathrm{UEPC}$ and $\mathrm{K}$ is the switch number in each leg.

As it can be seen, only one switch of each leg can be OFF in each status. Otherwise, if two or more switches are OFF in each leg, one or more outputs will be open circuit in the corresponding phase of that leg. As all outputs consist of inductance, open circuit status are not acceptable. By removing the non-authorised status, $(n+2)^{3}$ active and zero vectors can be achieved. Among these acceptable vectors, as it is shown in Table III, $6(n+1)$ vectors are individual active vectors for each output (see Fig. 4(a)), 12(n) vectors are common and the same active vectors for adjacent outputs (see Fig. 4(b)), 6 vectors are common and the same active vectors for all outputs (see Fig. 4(c)), 6(n) vectors are common and different active vectors for different outputs (see Fig. 4(d)), and finally $(n+2)$ vectors are zero vector for all outputs (see Fig. 4(e)). Since the outputs can experience various conditions at different operating states, the probability of having the same voltage and frequency for different outputs is low, which means the possibility of using the common vectors of all outputs in the simultaneous switching is also very low. In other words, in order to use simultaneous switching at any instant, it is necessary to have $6^{(n+1)}$ different switching states for outputs. Meanwhile, in accordance with Table III, only $(n+2)^{3}$ switching modes are acceptable for this converter, where $6(n+1)$ states can be used for simultaneous switching.

According to the above, only the switching states that generate the active vectors for an output and simultaneously generate the zero vectors for other outputs are used for independent control of the UEPC. These individual active vectors of each output make a space vector diagram, as shown in Fig. 5, for each output. The reference voltage of I-th output, which is generated by an individual controller of this output, can be written as follows:

$V_{\text {ref(I) }}=\left|V_{\text {ref (I) }}\right| \angle \alpha_{(I)}$

where

$\alpha_{(I)}=2 \pi f_{(I)} t+\theta_{(I)}$

where $f_{(I)}$ and $\theta_{(I)}$ are frequency and phase of I-th output. Firstly, to determine the switching signals for switches, the sectors in which the reference vector of each output is located should be calculated. Then, the adjacent vectors of each reference vector should be determined and switched to a specific time for each output. The time length assigned to each adjacent vector is calculated as follows:

$$
\begin{aligned}
& T_{1(I)}=\sqrt{3} / 2 m_{(I)} T_{s} \sin \left(\left(k_{(I)}\right) \pi / 3-\alpha_{(I)}\right) \\
& T_{2(I)}=\sqrt{3} / 2 m_{(I)} T_{s} \sin \left(\left(k_{(I)}-1\right) \pi / 3-\alpha_{(I)}\right) \\
& T_{0}=T_{s}-T_{1(1)}-T_{2(1)}-T_{1(2)}-T_{2(2)} \cdots \\
& \quad-T_{1(I)}-T_{2(I)} \ldots-T_{1(n+1)}-T_{2(n+1)} \\
& \quad=T_{s}-\sum_{I=1}^{n+1}\left(T_{1(I)}+T_{1(I)}\right) \\
& m_{(I)}=2\left|V_{r e f(I)}\right| / V_{d c}
\end{aligned}
$$

where $T_{1(I)}$ and $T_{2(I)}$ are time intervals of first and second 
TABLE IV

SEQUENCE OF ACTIVE AND ZeRO VeCtors TO MinimiZE THE SWITCHING LOSSES

\begin{tabular}{|c|c|c|c|c|c|c|c|c|c|c|c|c|c|c|c|c|}
\hline & 211 & 221 & 222 & 221 & 211 & 322 & 332 & 333 & 332 & 322 & $\ldots$ & $(\mathrm{I}+1, \mathrm{I}, \mathrm{I})$ & $(\mathrm{I}+1, \mathrm{I}+1, \mathrm{I})$ & $(\mathrm{I}+1, \mathrm{I}+1, \mathrm{I}+1)$ & $(\mathrm{I}+1, \mathrm{I}+1, \mathrm{I})$ & $(\mathrm{I}+1, \mathrm{I}, \mathrm{I})$ \\
\hline Port\#2 & $\mathrm{Z}$ & $\mathrm{Z}$ & $\mathrm{Z}$ & $\mathrm{Z}$ & $\mathrm{Z}$ & A & A & $\mathrm{Z}$ & A & A & $\ldots$ & $\mathrm{Z}$ & $\mathrm{Z}$ & $\mathrm{Z}$ & $\mathrm{Z}$ & $\mathrm{Z}$ \\
\hline$:$ & $:$ & $:$ & $:$ & $:$ & $:$ & $:$ & $:$ & $:$ & $:$ & $:$ & $\ldots$ & $:$ & $:$ & $:$ & $:$ & $:$ \\
\hline
\end{tabular}

Note: "A" and " $Z$ " mean Active and Zero states respectively and $\mathrm{T}_{0}^{\prime}$ is equal to $\mathrm{T}_{0} /(\mathrm{n}+1)$.

TABLE V

CURRENT AMPLITUDE OF EACH SWITCH IN LEG A FOR DIFFERENT STATES

\begin{tabular}{|c|c|c|c|c|c|c|c|}
\hline & $\mathrm{S}_{\mathrm{A} 1}=\mathrm{OFF}$ & $\mathrm{S}_{\mathrm{A} 2}=\mathrm{OFF}$ & $\mathrm{S}_{\mathrm{A} 3}=\mathrm{OFF}$ & $\ldots$ & $\mathrm{S}_{\mathrm{A}(\mathrm{n})}=\mathrm{OFF}$ & $S_{A(n+1)}=O F F$ & $\mathbf{S}_{\mathrm{A}(\mathrm{n}+2)}=\mathrm{OFF}$ \\
\hline isA1 $_{\text {SA }}$ & 0 & $-\mathrm{I}_{1}$ & $-\left(I_{1}+I_{2}\right)$ & $\ldots$ & $-\left(\mathrm{I}_{1}+\mathrm{I}_{2}+\mathrm{I}_{3}+\ldots+\mathrm{I}_{\mathrm{n}-1}\right)$ & $-\left(\mathrm{I}_{1}+\mathrm{I}_{2}+\mathrm{I}_{3}+\ldots+\mathrm{I}_{\mathrm{n}-1}+\mathrm{I}_{\mathrm{n}}\right)$ & $-\left(I_{1}+I_{2}+I_{3}+\ldots+I_{n-1}+I_{n}+I_{n+1}\right)$ \\
\hline isA2 $_{\mathrm{SA}}$ & $\mathrm{I}_{1}$ & 0 & $-\mathrm{I}_{2}$ & $\ldots$ & $-\left(\mathrm{I}_{2}+\mathrm{I}_{3 \ldots} \ldots+\mathrm{I}_{\mathrm{n}-1}\right)$ & $-\left(I_{2}+I_{3} \ldots+I_{n-1}+I_{n}\right)$ & $-\left(I_{2}+I_{3} \ldots+I_{n-1}+I_{n}+I_{n+1}\right)$ \\
\hline$i_{\mathrm{SA} 3}$ & $\mathrm{I}_{1}+\mathrm{I}_{2}$ & $\mathrm{I}_{2}$ & 0 & $\ldots$ & $-\left(\mathrm{I}_{3}+\ldots+\mathrm{I}_{\mathrm{n}-1}\right)$ & $-\left(I_{3}+\ldots+I_{n-1}+I_{n}\right)$ & $-\left(I_{3}+\ldots+I_{n-1}+I_{n}+I_{n+1}\right)$ \\
\hline$:$ & $:$ & $:$ & $:$ & $\ldots$ & $:$ & $:$ & $:$ \\
\hline $\mathbf{i}_{\mathbf{S A}(\mathbf{n})}$ & $\mathrm{I}_{1}+\mathrm{I}_{2}+\ldots+\mathrm{I}_{\mathrm{n}-1}$ & $\mathrm{I}_{2}+\ldots+\mathrm{I}_{\mathrm{n}-1}$ & $\mathrm{I}_{3}+\ldots+\mathrm{I}_{\mathrm{n}-1}$ & $\ldots$ & 0 & $-I_{n}$ & $-\left(I_{n}+I_{n+1}\right)$ \\
\hline$i_{\text {is }(\mathbf{n}+1)}$ & $\mathrm{I}_{1}+\mathrm{I}_{2}+\ldots+\mathrm{I}_{\mathrm{n}-1}+\mathrm{I}_{\mathrm{n}}$ & $\mathrm{I}_{2}+\ldots+\mathrm{I}_{\mathrm{n}-1}+\mathrm{I}_{\mathrm{n}}$ & $\mathrm{I}_{3}+\ldots+\mathrm{I}_{\mathrm{n}-1}+\mathrm{I}_{\mathrm{n}}$ & $\ldots$ & $\mathrm{I}_{\mathrm{n}}$ & 0 & $-I_{n+1}$ \\
\hline $\mathbf{i}_{\mathbf{S A}(\mathbf{n}+2)}$ & $\mathrm{I}_{1}+\mathrm{I}_{2}+\ldots+\mathrm{I}_{\mathrm{n}-1}+\mathrm{I}_{\mathrm{n}}+\mathrm{I}_{\mathrm{n}+1}$ & $\mathrm{I}_{2}+\ldots+\mathrm{I}_{\mathrm{n}-1}+\mathrm{I}_{\mathrm{n}}+\mathrm{I}_{\mathrm{n}+1}$ & $\mathrm{I}_{3}+\ldots+\mathrm{I}_{\mathrm{n}-1}+\mathrm{I}_{\mathrm{n}}+\mathrm{I}_{\mathrm{n}+1}$ & $\ldots$ & $\mathrm{I}_{\mathrm{n}}+\mathrm{I}_{\mathrm{n}+1}$ & $I_{n+1}$ & 0 \\
\hline
\end{tabular}

adjacent active vectors of I-th output, $m_{(I)}$ is modulation index for I-th output, $k_{(I)}$ is identified sector for I-th output, $T_{s}$ is switching time, $T_{0}$ is time interval of zero vector and $V_{d c}$ is DClink voltage.

In SSVM, the adjacent active vectors of outputs in each sector are switched sequentially. If the total time interval of the active vectors does not cover the switching time, the switching of the zero vectors will be needed. The type of zero vectors can be selected with respect to control and optimization targets such as minimization of number of semiconductor switchings [28]. Because the UEPC is used for integration of the low power VSWTS-PMSGs, in this study, the main aim is to minimize the switching loss. Therefore, the zero vectors type and their positions are selected in such a way that the minimum changes in the status of the switches occur. To clarify how the SSVM works, the sequence of the active and zero vectors has been shown in Table IV when the identified sector for all outputs is one.

\section{DC-link Voltage Design}

In the conventional structures for integration of PMSGs, the DC-link energy is available for all connected converters during the switching time. However, in the proposed structure, because of using the SSVM to control the outputs autonomously, this energy will be available for each output only in a fraction of the switching time. In the same condition, in order to have the same dynamic response for the outputs as well as DC-link voltage, a larger DC-link voltage is required in the UEPC. This requirement can be proved mathematically. By re-writing (5), the switching time can be determined as:

$T_{s}=T_{0}+\sum_{I=1}^{n+1}\left(T_{1(I)}+T_{1(I)}\right)$

The maximum time interval for the switching of active vectors will be achieved when:

$T_{s}=\sum_{I=1}^{n+1}\left(T_{1(I)}+T_{1(I)}\right)$

By substituting (4) and (5) into (8), we get:

$$
\begin{aligned}
T_{s}=\sum_{I=1}^{n+1}( & \sqrt{3} / 2 m_{(I)} T_{s} \sin \left(\left(k_{(I)}\right) \pi / 3-\alpha_{(I)}\right) \\
& \left.+\sqrt{3} / 2 m_{(I)} T_{s} \sin \left(\left(k_{(I)}-1\right) \pi / 3-\alpha_{(I)}\right)\right)
\end{aligned}
$$

For validity of above relation, the right side of this equation must be in its maximum value. This happens when

$\alpha_{(I)}=2\left(k_{(I)}-1\right) \pi / 6$

By substituting (10) into (9), we have:

$2 / \sqrt{3}=\sum_{I=1}^{n+1} m_{(I)}$

The final relation for designing the DC-link voltage will be achieved by inserting (6) into (11) as follows:

$V_{d c}=\sqrt{3} \sum_{I=1}^{n+1} V_{r e f(I)}$

From (13), the DC-link voltage must be at least $\sqrt{3}$ times larger than the sum of the nominal output voltages.

\section{Rating of Components}

According to the SSVM, at any moment in time, the UEPC will be in active mode for one of the outputs and zero mode for others, which means all switches are used for applying the active vectors to the active output and at the same time zero vectors to the others. With respect to [29]-[31] in which have compared the nine-switch converter's loss with back-to-back converter, it can be proved that upper and lower switches in UEPC may have highest instantaneous current although the middle switches may have lower instantaneous current. For the UEPC, instantaneous currents, which can pass through the switches in leg A for different states of this leg can be summarized as given in Table $\mathrm{V}$, where $I_{i}$ is the current of $i$-th output and $1 \leq i \leq n+1$. According to analysis done by [29]-[31], the current rating of each switch depends on polarity, amplitude, frequency and phase of outputs currents and voltages. In wind farm application, since the grid absorbs power and PMSGs inject current and also since the frequency of PMSGs are less than the grid frequency, as it has been explained by [31], the current will be less than what it is calculated in Table V. On the other hand, the stress voltage over the switches 


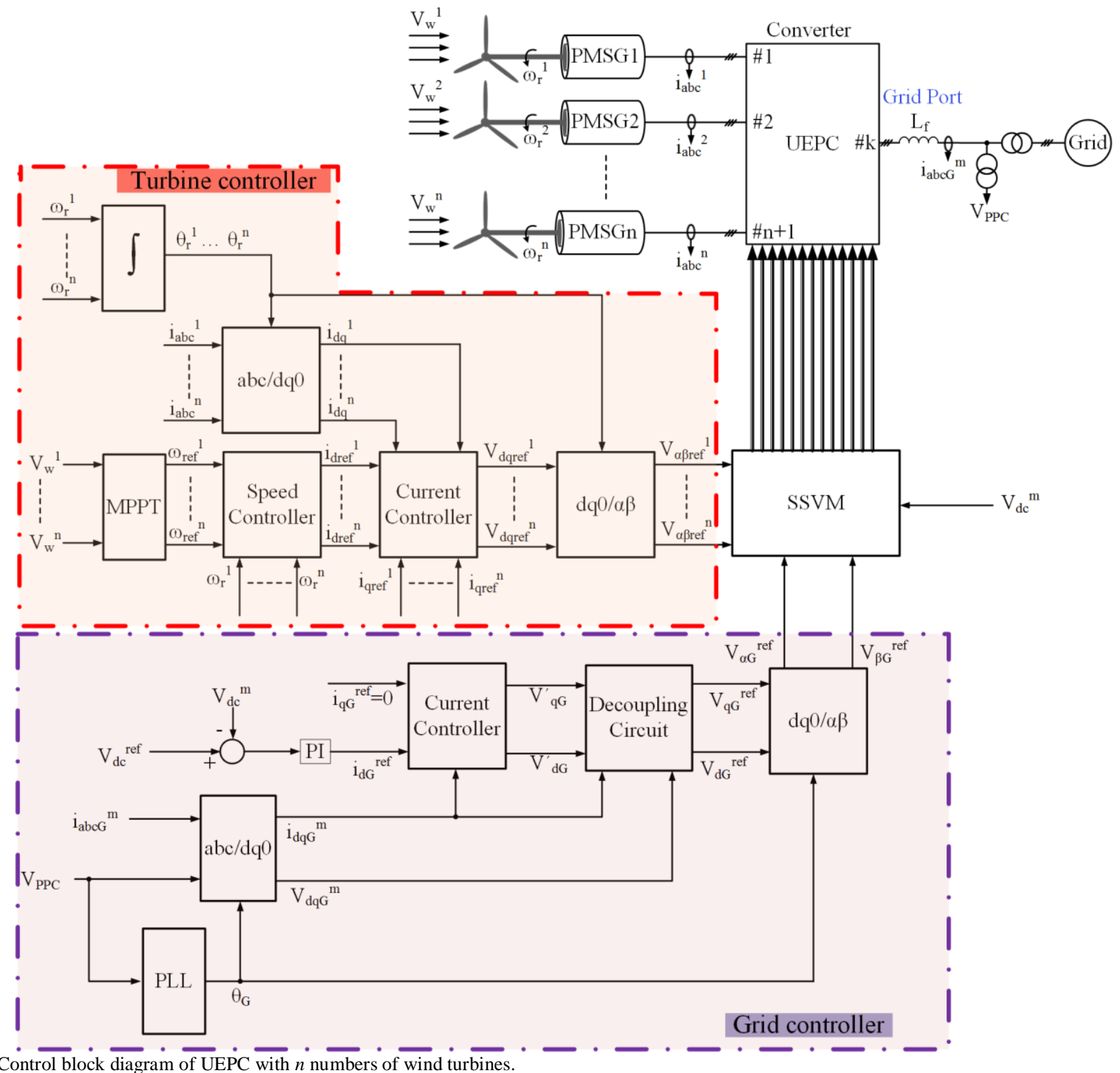

Fig. 6. Control block diagram of UEPC with $\dot{n}$ numbers of wind turbines.

is equal to DC-link voltage.

\section{AutonOmous CONTROLLER For VARIOUS OUTPuTs}

\section{A. MPPT Controller for PMSGs}

The final relation for the mechanical power captured from the wind can be expressed as follows [32]:

$P_{w}=0.5 \rho \pi R^{2} V_{w}^{3} C_{P}(\lambda, \beta)$

where $P_{w}$ is the captured power from the wind, $\rho$ is the air density $\left[\mathrm{kg} / \mathrm{m}^{3}\right], R$ is the blade radius $[\mathrm{m}], V_{w}$ is the wind speed $[\mathrm{m} / \mathrm{s}]$ and $C_{p}$ is the power coefficient, which is a function of both tip speed ratio, $\lambda$, and blade pitch angle, $\beta[\mathrm{deg}]$. The tip speed ratio and $C_{p}$ can be written as follows:

$$
\begin{aligned}
& \lambda=\frac{\omega_{r} R}{V_{w}} \\
& C_{p}=0.73\left(\frac{151}{\lambda_{i}}-0.58 \beta-0.002 \beta^{2.14}-13.2\right) e^{-18.4 / \lambda_{i}}
\end{aligned}
$$

where

$$
\lambda_{i}=\left(\frac{1}{\lambda-0.02 \beta}+\frac{0.003}{\beta^{3}+1}\right)^{-1}
$$

The pitch angle controller will be in effect when the wind speed is above the nominal wind speed in order to keep the output power equal to the nominal active power of the PMSG [33]. Under other conditions, it is constant and equal to zero. Since the wind speed patterns, which are considered in this paper are under the nominal wind speed, the pitch angle will be zero.

For a given wind speed and pitch angle (that is zero), there will be an optimal rotational speed of the wind turbine that gives optimal tip-speed ratio. It is vital to keep the rotor speed at optimum value to maximize the captured power from the wind. This will be performed by maximum power point tracking (MPPT) control, which keeps $C_{p}$ at the maximum value $C_{p, \max }$. The maximum power captured from the wind can be written as:

$P_{w, \max }=0.5 \rho \pi R^{2}\left(\frac{R}{\lambda_{\text {opt }}}\right)^{3} C_{p, \max } \omega_{r, o p t}^{3}=K_{o p t} \omega_{r, o p t}^{3}$ 
TABLE VI

PARAMETERS OF VSWTS-PMSGS

\begin{tabular}{|c|c|c|c|}
\hline $\begin{array}{l}\text { Parameters of } \\
\text { Turbines }\end{array}$ & Value & Parameters of PMSGs & Value \\
\hline $\begin{array}{l}\text { Radius of the turbines } \\
R(\mathrm{~m})\end{array}$ & 3.7 & Number of pole-pairs & 8 \\
\hline Numbers of blade & 3 & $\begin{array}{c}\text { Moment of inertia of the } \\
\text { generator } \\
J_{g}\left(\mathrm{~kg} . \mathrm{m}^{2}\right)\end{array}$ & 0.32 \\
\hline $\begin{array}{c}\text { Moment of inertia of } \\
\text { the blade } \\
J_{r}\left(\mathrm{~kg} \cdot \mathrm{m}^{2}\right)\end{array}$ & 38 & $\begin{array}{l}\text { Permanent magnet flux } \\
\varphi(\mathrm{wb})\end{array}$ & 1.28 \\
\hline Rated Power $P_{r}(\mathrm{~kW})$ & 10 & $\begin{array}{c}\text { Rated generator speed } \\
\omega_{g N}(\mathrm{rad} / \mathrm{s})\end{array}$ & 23 \\
\hline $\begin{array}{c}\text { Max power } \\
\text { coefficient } C_{p \max }\end{array}$ & 0.35 & $\begin{array}{c}\text { Winding Resistance } R_{r} \\
(\Omega)\end{array}$ & 1.3 \\
\hline $\begin{array}{l}\text { Optimum tip speed } \\
\text { ratio } \lambda_{\text {opt }}\end{array}$ & 8.2 & $\begin{array}{l}\text { Winding inductance } L \\
(\mathrm{mH})\end{array}$ & 3.6 \\
\hline $\begin{array}{c}\text { Rated wind velocity } \\
V_{N}(\mathrm{~m} / \mathrm{s})\end{array}$ & 10.5 & DC-link voltage $V_{d c}(\mathrm{~V})$ & 1800 \\
\hline $\begin{array}{c}\text { Rated rotor speed } \omega_{r N} \\
(\mathrm{rad} / \mathrm{s})\end{array}$ & 23 & $\begin{array}{c}\text { DC-link capacitor } C_{d c} \\
(\mathrm{uF})\end{array}$ & 5000 \\
\hline \multicolumn{3}{|c|}{ Grid side voltage $V_{L L}(\mathrm{~V})$} & 400 \\
\hline
\end{tabular}

The control strategy for PMSGs using proposed UEPC is shown in Fig. 6. All PMSGs are controlled in the synchronous reference frame with a rotational speed equal to the rotational speed of each PMSG. After finding the optimum value of rotational speed for each PMSG with respect to their wind speeds, their reference speeds are compared to the actual speeds. By the use of the PI controller as a speed controller, the reference values for $\mathrm{d}$-axis currents are determined. To reduce the copper loss and losses of the whole systems as much as possible, the reference values for the q-axis currents of the PMSGs can be considered zero. Finally, the dq-axis reference voltages can be achieved by using another PI controller as a current controller for each PMSG.

\section{B. Control of the Grid Port}

The target of the grid port controller is to keep the DC-link voltage constant so that the active power generated by the PMSGs is fed to the grid [34]. This aim will be achieved by adjusting the d-axis current. Furthermore, the reactive power fed to the grid can be controlled by q-axis current regulation. However, in this paper, in order to achieve unity power factor in the grid side, the reference value for q-axis current is considered zero. The well-known control scheme as shown in Fig. 6, which works in a synchronous reference frame that rotates synchronously with the grid voltage, is used as the control strategy for grid port. As it is shown, the grid side voltage phasor is synchronized with the controller reference frame by using a phase locked loop (PLL).

\section{RESUlts AND Discussions}

In order to examine the possibility of using the proposed UEPC and its SSVM for grid integration of the AC sources, two VSWTS-PMSGs with the parameters shown in Table VI [35], have been integrated to the grid through this converter. In this case, the number of outputs and number of switches in each leg should be three and four, respectively. The simulations have been run for two scenarios. Firstly, to make how the UEPC works more intelligible, a step change in wind speed of both PMSGs will be applied. Then, in order to demonstrate the

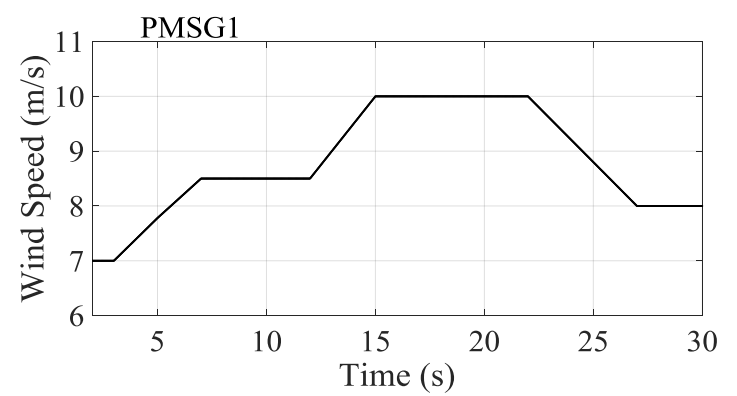

(a)

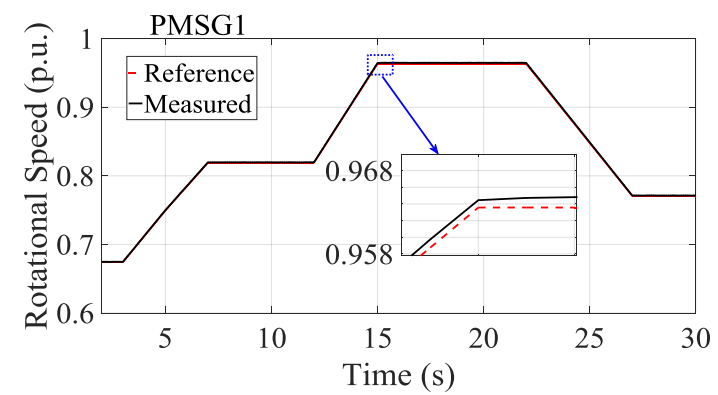

(b)

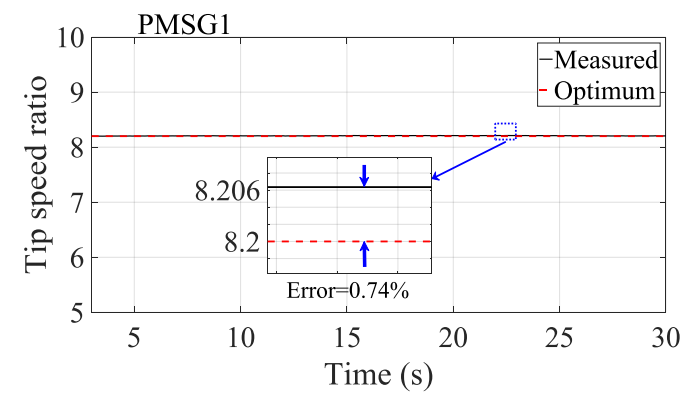

(c)

Fig. 7. Simulation results for step response, (a) wind speed for PMSG1, (b) rotational speed of PMSG1, and (c) tip speed ratio of PMSG1.

results closer to reality, real wind speed data taken from Hokkaido Island of Japan has been used with PMSGs.

\section{A. Step Response}

It is noted that because of the turbine's inertia, sudden step change will make the output power of PMSGs negative, which means the PMSGs will work in motor region. Therefore, two smooth step changes for first scenario as they are shown in Fig. 7(a) and 8(a), are applied to the turbines. It is noted that different speeds are applied to the PMSGs to depict the effective performance of the UEPC. As shown in Fig. 7(b) and 8(b), the speed controllers act effectively so that the rotational speeds of both PMSGs track their optimum values. As a result, the tip speed ratios as shown in Fig. 7(c) and 8(c), are coincident with the optimum value. That means the maximum power are extracted from the wind for both PMSGs.

The grid side current along with its Fast Fourier Transform (FFT) spectrum are shown in Fig. 8(d) and 8(e), respectively. It is clear that because of the use SSVM, the total harmonic distortion of the grid side is within an acceptable range. The generated active powers by the PMSGs and injected power to the grid are shown in Fig. 9(a), Fig. 9(b) and Fig. 9(c), respectively. As it can be seen that the total generated power approximately equals to the injected powers by PMSGs. 


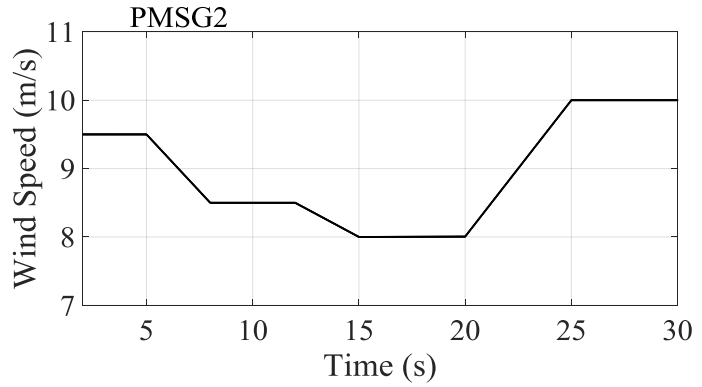

(a)

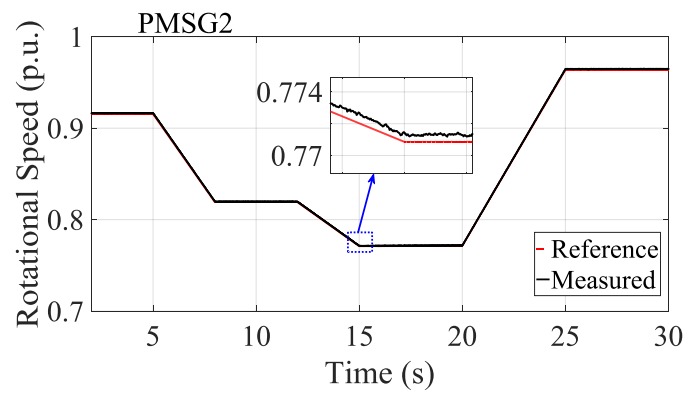

(b)

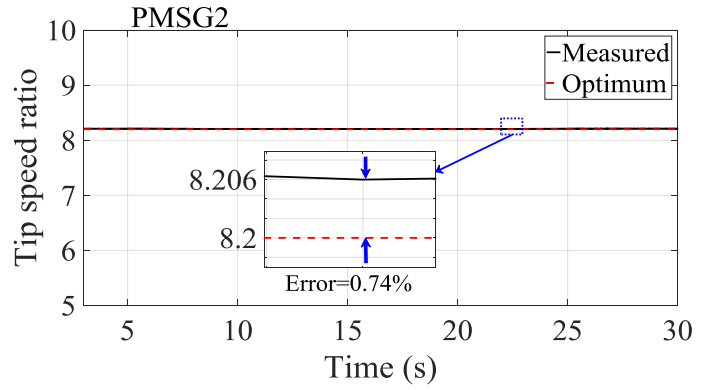

(c)

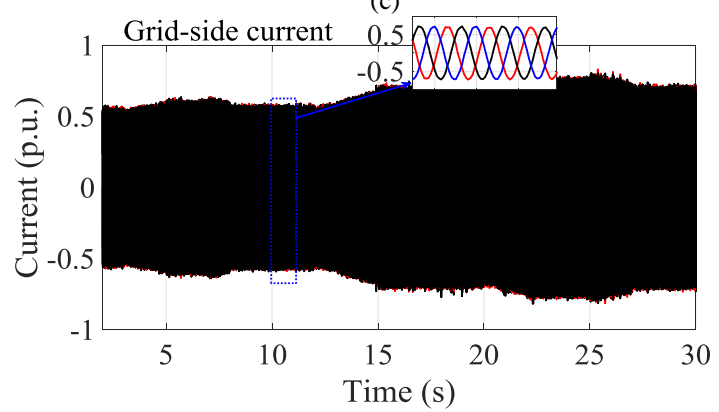

(d)

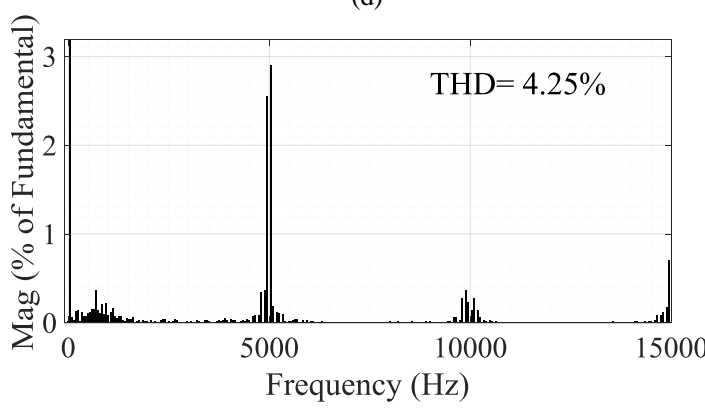

(e)

Fig. 8. Simulation results for step response, (a) wind speed for PMSG2, (b) rotational speed of PMSG2, (c) tip speed ratio of PMSG2, (d) grid side current, and (e) FFT spectrum of the grid current.

Because of this power flow, it is expected to have constant DClink voltage. As shown in Fig. 9(e), the DC-link voltage

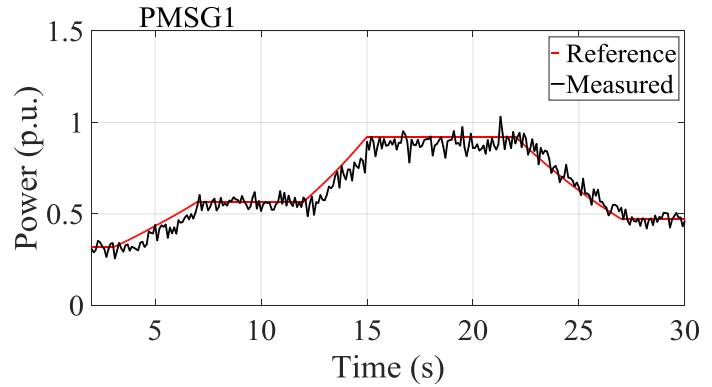

(a)

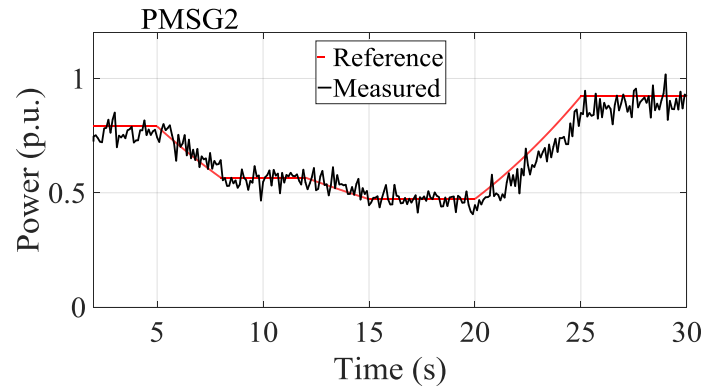

(b)

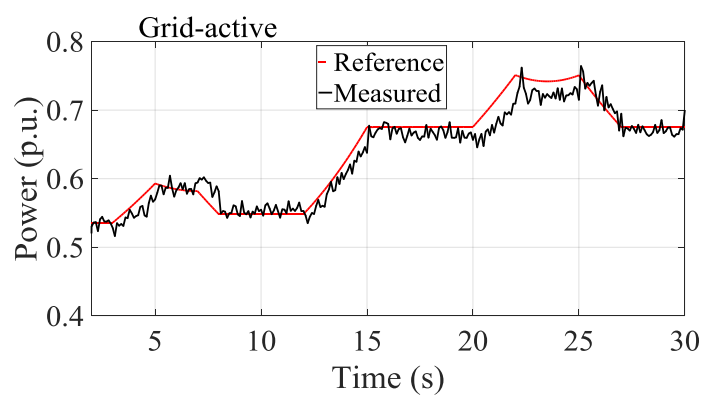

(c)

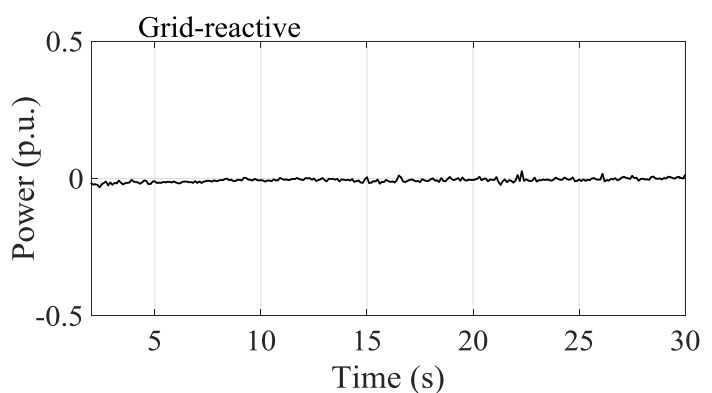

(d)

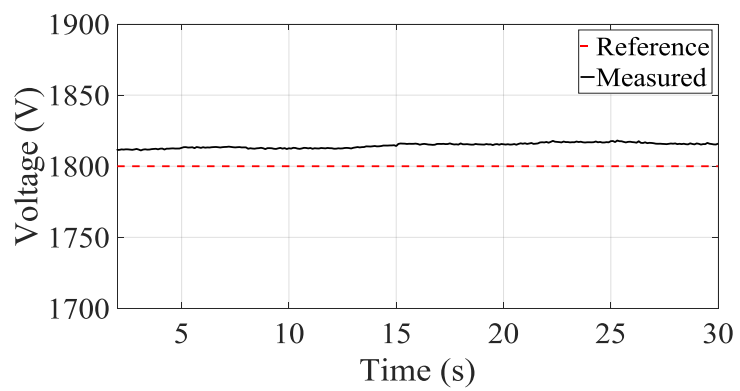

(e)

Fig. 9. Simulation results for step response, (a) generated power by PMSG1, (b) generated power by PMSG2, (c) grid active power, (d) grid reactive power, and (e) DC-link voltage.

changes like the injected power to the grid and is approximately constant. From Fig. 9(d), the reactive power injected to the grid 


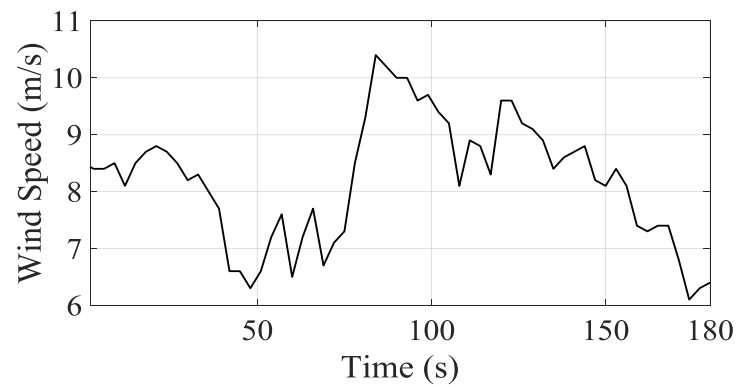

(a)

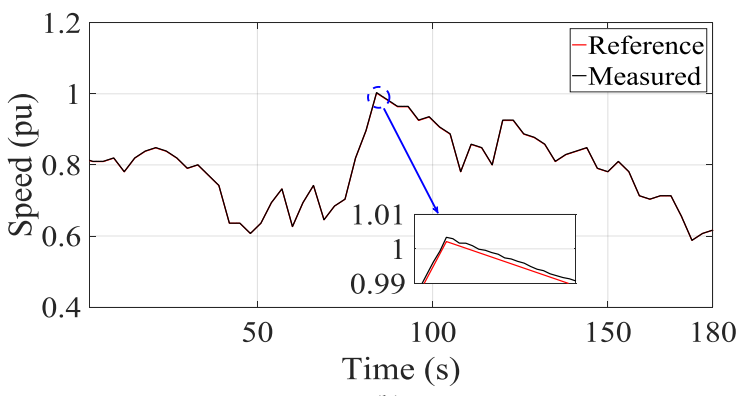

(b)

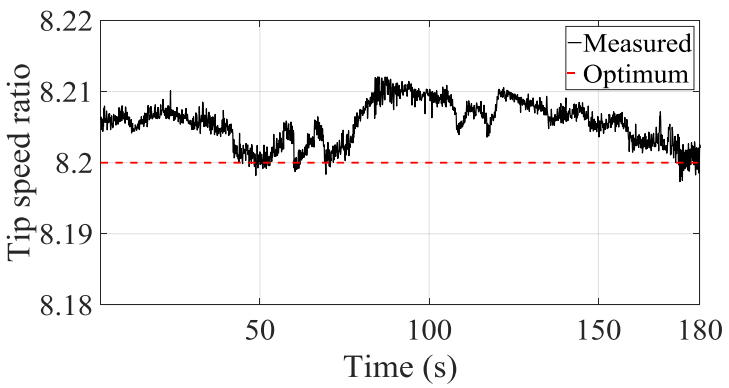

(c)

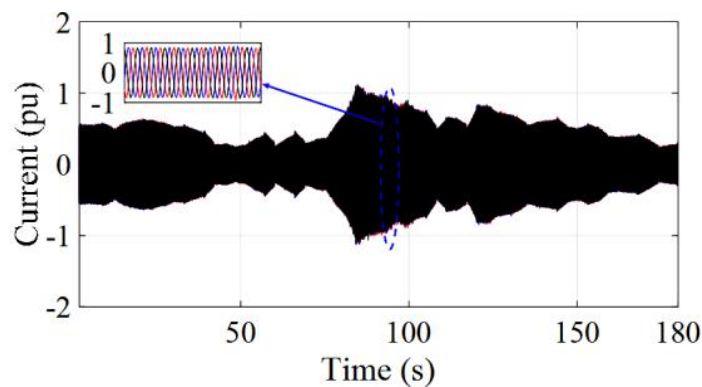

(d)

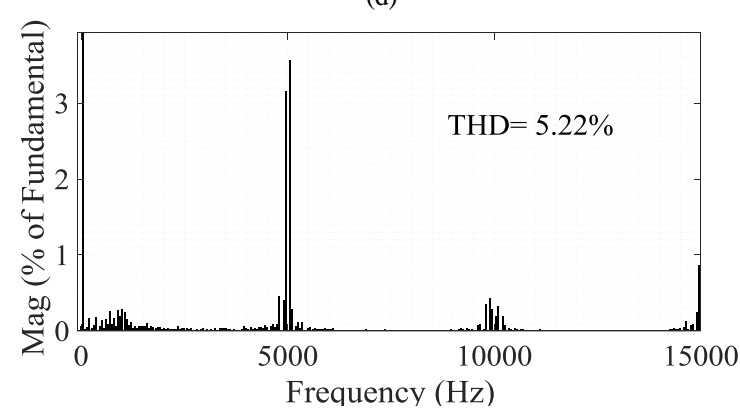

(e)

Fig. 10. Simulation results in a real wind scenario, (a) wind speed, (b) rotational speed, (c) tip speed ratio, (d) grid side current, and (e) FFT spectrum of the grid currents.

is zero, as it is expected.

\section{B. Validation using Real Wind Data}

As it is mentioned earlier in order to examine the performance of the UEPC, a real wind speed pattern, which is shown in Fig. 10(a) is applied to both PMSGs. Fig. 10(b) shows the actual rotational speed of PMSGs and its optimum value that is optimized by the MPPT. This error-free tracking of the optimum speed guarantees the maximization of the captured power from the wind (Fig. 10(c)). To verify the ability of the UEPC to inject the appropriate current to the grid, three phase currents of the grid and their FFT spectrum are shown in Fig. 10(d) and 10(e), respectively. From Fig. 11(a) and Fig. 11(b) it can be concluded that the PMSG's controller works appropriately so that the output power of each PMSG is well matched with the applied wind speed. Fig. 11(c) exhibits the injected active power to grid that confirms the appropriate performance of the voltage controller. By taking into account of Fig. 11(d), which is related to injected reactive power to grid, the unity power factor operation of the grid side converter is validated. In spite of the wind fluctuations and therefore the power produced by PMSGs, as shown in Fig. 11(e), the DClink voltage is almost constant.

\section{CONCLUSION}

In this paper, an UEPC for grid integration of the VSWTSPMSGs has been presented. The design and operation principle of the proposed converter have been demonstrated along with proposed switching scheme based on sequential space vector modulation. The autonomous controller developed in this study can maintain MPPT of PMSGs in a wind farm regardless of which output is connected to the grid. The proposed controller can also maintain the DC-link voltage and unity power factor at the grid side. The performance of the proposed UEPC and developed controllers are verified using extensive simulation analysis. The proposed converter provides compactness and can interface two or more bidirectional output ports for the PMSGs and grid and also energy storages. It has been clearly demonstrated that for integrating $n$ number of PMSGs in a wind farm, the UEPC requires $3(n)$ and $3(3 n-2)$ less number of switches compared to the conventional converters used in DC and $\mathrm{AC}$ based wind farm topologies, respectively. This means if a wind farm has 5 PMSGs, there will be a reduction in number of switches of $65 \%$ and $41.6 \%$ in AC and DC based wind farm topologies compared to the UEPC. The processing power requirements for the real time implementation of the proposed UEPC is also less compared to other AC and DC-link based topologies. These may reduce the investment cost in a wind farm.

\section{REFERENCES}

[1] V. Yaramasu, and B. Wu, "Predictive Control of a Three-Level Boost Converter and an NPC Inverter for High-Power PMSG-Based Medium Voltage Wind Energy Conversion Systems," IEEE Trans. Power Electron., vol. 29, no. 10, pp. 5308-5322, Oct. 2014.

[2] J. C. Y. Hui, A. Bakhshai, and P. K. Jain, "An Energy Management Scheme With Power Limit Capability and an Adaptive Maximum Power Point Tracking for Small Standalone PMSG Wind Energy Systems," IEEE Trans. Power Electron., vol. 31, no. 7, pp. 4861-4875, Jul. 2016.

[3] K. H. Tan, "Squirrel-Cage Induction Generator System Using Wavelet Petri Fuzzy Neural Network Control for Wind Power Applications," IEEE Trans. Power Electron., vol. 31, no. 7, pp. 5242-5254, Jul. 2016. 


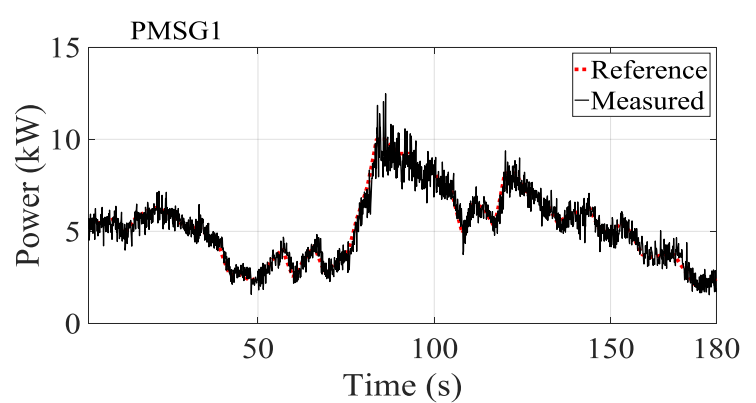

(a)

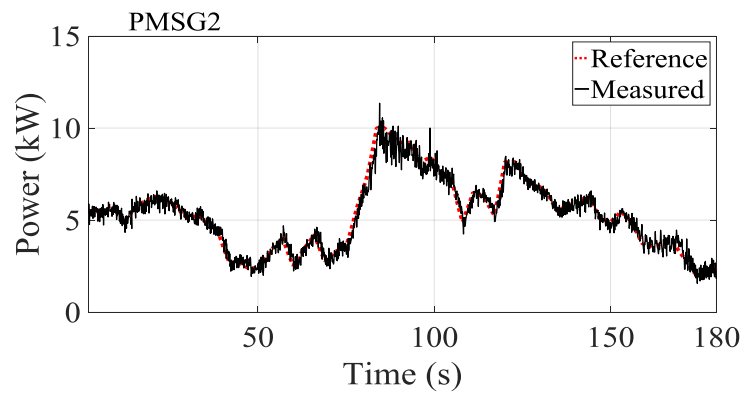

(b)

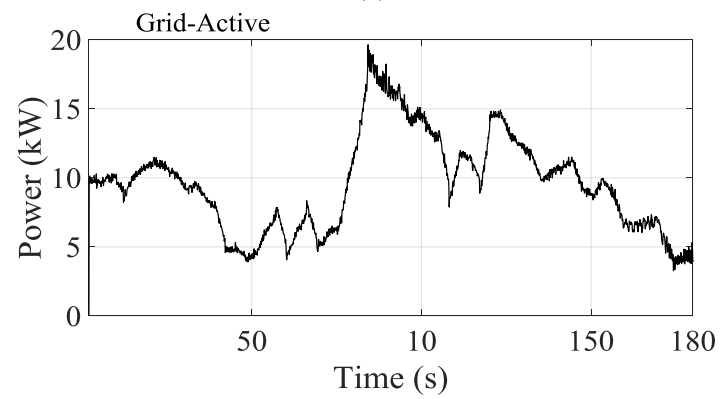

(c)

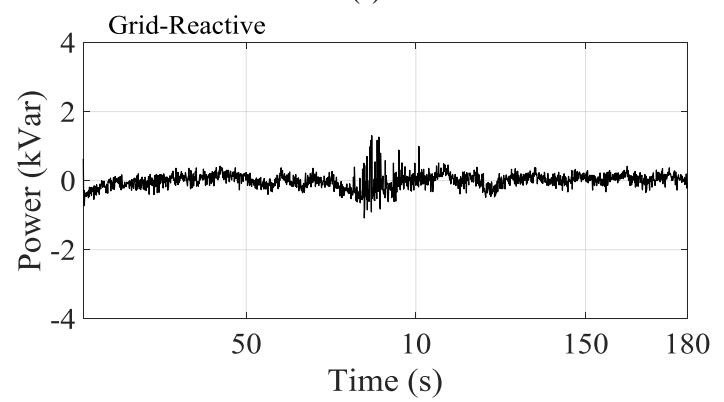

(d)

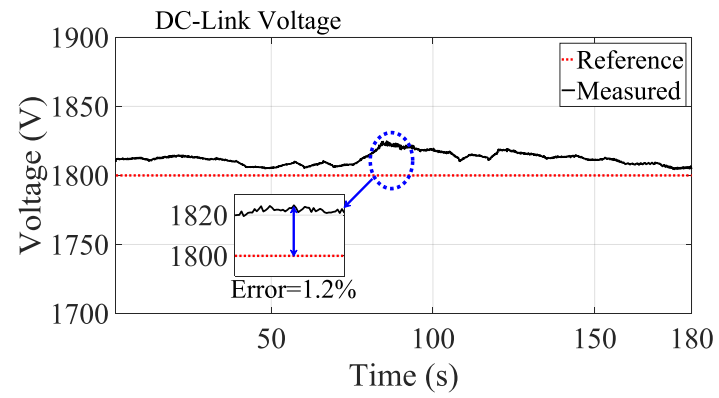

(e)

Fig. 11. Simulation results in a real wind scenario, (a) generated power by PMSG1, (b) generated power by PMSG2, (c) grid active power, (d) grid reactive power, and (e) DC-link voltage.

[4] S. Li, T. A. Haskew, R. P. Swatloski, and W. Gathings, "Optimal and Direct-Current Vector Control of Direct-Driven PMSG Wind Turbines," IEEE Trans. Power Electron., vol. 27, no. 5, pp. 2325-2337, May 2011.
[5] S. M. Muyeen, J. Tamura, and T. Murata, Stability Augmentation of a Grid-connected Wind Farm, Springer-Verlag London, ISBN 978-184800-315-6, October 2008.

[6] S. Shibata, H. Yamada, T. Tanka, and M. Okomoto, "Reduced-Capacity Inrush Current Suppressor Using a Matrix Converter in a Wind Power Generation System with Squirrel-Cage Induction Machines," Energies, vol. 9, no. 3, pp. 50-60, Mar. 2016.

[7] M. Abdelrahem, C. M. Hacki, and R. Kennel, "Finite Position Set-Phase Locked Loop for Sensorless Control of Direct-Driven Permanent-Magnet Synchronous Generators," IEEE Trans. Power Electron., vol. 33, no. 4, pp. 3097-3105, Apr. 2018.

[8] S. M. Tripathi, A. N. Tiwari, and D. Singh, "Grid-integrated permanent magnet synchronous generator based wind energy conversion systems: A technology review," Renewable and Sustainable Energy Reviews., vol. 51, pp. 1288-1305, Nov. 2015.

[9] R. Errouissi, and A. Al-Durra, "A Novel PI-type Sliding Surface for PMSG-based Wind Turbine with Improved Transient Performance," IEEE Trans. Energy Convers., vol. PP, no. 99, pp. 1-1, in press.

[10] S. M. Muyeen, R. Takahashi, T. Mirata, and J. Tamura, "Integration of an energy capacitor system with a variable-speed wind generator," IEEE Trans. Energy Convers., vol. 24, no. 3, pp. 740-749, Sep. 2009.

[11] N. K. S. Naidu, and B. Singh "Experimental Implementation of Doubly Fed Induction Generator-Based Standalone Wind Energy Conversion System," IEEE Trans. Ind. Appl., vol. 52, no. 4, pp. 3332-3339, Jul. 2016.

[12] J. Hu, H. Yuan, and X. Yuan, "Modeling of DFIG-Based WTs for SmallSignal Stability Analysis in DVC Timescale in Power Electronized Power Systems," IEEE Trans. Energy Convers., vol. 32, no. 3, pp. 1151-1165, Sep. 2017.

[13] H. Nian, P. Cheng, and Z. Q. Zhu, "Independent Operation of DFIGBased WECS Using Resonant Feedback Compensators Under Unbalanced Grid Voltage Conditions," IEEE Trans. Power Electron., vol. 30, no. 7, pp. 3650-3661, Jul. 2015.

[14] Z. Chen, J. M. Guerrero, and F. Blaabjerg, "A Review of the State of the Art of Power Electronics for Wind Turbines," IEEE Trans. Power Electron., vol. 24, no. 8, pp. 1859-1876, Aug. 2009.

[15] S. A. Amamra, K. Meghriche, A. Cherifi, and B. Francois, "Multilevel Inverter Topology for Renewable Energy Grid Integration," IEEE Trans. Ind. Electron., vol. 64, no. 11, pp. 8855-8867, Nov. 2017.

[16] S. Debnath, and M. Saeedfard, "A New Hybrid Modular Multilevel Converter for Grid Connection of Large Wind Turbines," IEEE Trans. Sustain. Energy, vol. 4, no. 4, pp. 1051-1065, Oct. 2013.

[17] Z. Zhang, C. M. Hackl, and R. Kennel, "Computationally Efficient DMPC for Three-Level NPC Back-to-Back Converters in Wind Turbine Systems With PMSG," IEEE Trans. Power Electron., vol. 32, no. 10, pp. 80188035, Oct. 2017.

[18] J. S. Lee, K. B. Lee, and F. Blaabjerg, "Open-Switch Fault Detection Method of a Back-to-Back Converter Using NPC Topology for Wind Turbine Systems," IEEE Trans. Ind. Appl., vol. 51, no. 1, pp. 325-336, Jan. 2015

[19] A. Chub, O. Husev, A. Blinov, and D. Vinnikov, "Novel Isolated Power Conditioning Unit for Micro Wind Turbine Applications," IEEE Trans. Ind. Electron., vol. 64, no. 7, pp. 5984-5994, Jul. 2017.

[20] A. H. Rajaei, M. Mohamadian, and A. Yazdian Varjani, "ViennaRectifier-Based Direct Torque Control of PMSG for Wind Energy Application," IEEE Trans. Ind. Electron., vol. 60, no. 7, pp. 2919-2930, Jul. 2013.

[21] H. S. Krishnamoorthy, D. Rana, P. Garg, P. N. Enjeti, and I. J. Pitel, "Wind Turbine Generator-Battery Energy Storage Utility Interface Converter Topology With Medium-Frequency Transformer Link," IEEE Trans. Power Electron., vol. 25, no. 6, pp. 1488-1496, Jun. 2010.

[22] M. Azizi, M. Mohamadian, and R. Beiranvand, "A New Family of MultiInput Converters Based on Three Switches Leg," IEEE Trans. Ind. Appl., vol. 63, no. 11, pp. 6812-6823, Nov. 2016.

[23] A. Ajami, R. Alizadeh, and M. Elmi, "Design and control of a grid tied 6switch converter for two independent low power wind energy resources based on PMSGs with MPPT capability," Renew. Energy, vol. 87, no. 1, pp. 532-543, Mar. 2016.

[24] M. Heydari, A. Yazdian, M. Mohamadian, and H. Zahedi, "A Novel Variable-Speed Wind Energy System Using Permanent-Magnet Synchronous Generator and Nine-Switch AC/AC Converter," in Proc. of PEDSTC, Feb. 2011, pp. 5-11.

[25] M. Elmi, R. Alizadeh, and A. Ajami, "A Reduced Switch Multi-Input Converter for Low Power Variable Speed Wind Turbine Application," in Proc. of PEDSTC, Feb. 2015, pp. 207-303. 
[26] C. A. Reusser, S. Kouro, and R. Cardenas, "Dual three-phase PMSG based wind energy conversion system using 9-switch dual converter," in Proc. IEEE Energy Convers. Cong. Expo, Sep. 2015, pp. 1021-1027.

[27] V. Yaramasu, A. Dekka, M. J. Duran, S. Kouro, and B. Wu, "PMSGbased wind energy conversion systems: survey on power converters and controls," IET Electric Power Appl., vol. 11, no. 6, pp. 956-968, Jul. 2017.

[28] S. M. Dehghan, M. Mohamadian, A. Yazdan, and F. Afsharzadeh, "Space Vectors Modulation for Nine-Switch Converters," IEEE Trans. Power Electron., vol. 25, no. 6, pp. 1488-1496, Jun. 2010.

[29] K. Ali, P. Das, and S. K. Panda, "A Special Application Criterion of the Nine-Switch Converter With Reduced Conduction Loss," IEEE Trans. Ind. Electron., vol. 65, no. 4, pp. 2853-2863, Apr. 2018.

[30] Z. Qin, P. C. Loh, and F. Blaabjerg, "Application Criteria for Nine-Switch Power Conversion Systems with Improved Thermal Performance, ” IEEE Trans. Power Electron., vol. 30, no. 8, pp. 4608-4620, Aug. 2015.

[31] P. C. Loh, A. S. Bahman, Z. Qin, and F. Blaabjerg, "Evaluation of switch currents in nine-switch energy conversion systems," in Proc. IEEE IECON, Nov. 10-13, 2013, pp. 755-760.

[32] S. M. Muyeen, R. Takahashi, T. Murata, and J. Tamura, "A variable speed wind turbine control strategy to meet wind farm grid code requirements," IEEE Trans. Power Syst., vol. 25, no. 1, pp. 331-340, Feb. 2010.

[33] Y. S. Kim, I. Y. Chung, and S. I. Moon, "Tuning of the PI Controller Parameters of a PMSG Wind Turbine to Improve Control Performance under Various Wind Speeds," Energies, vol. 8, no. 2, pp. 1406-1425, Feb. 2015.

[34] S. M. Muyeen, R. Takahashi, T. Murata, and J. Tamura, "Control of Permanent-Magnet Generators Applied to Variable-Speed Wind-Energy Systems Connected to the Grid," IEEE Trans. Energy Convers., vol. 21, no. 1, pp. 130-136, Mar. 2006.

[35] J. Chen, J. Chen, C. Gong, "On optimizing the aerodynamic load acting on the turbine shaft of PMSG-based direct-drive wind energy conversion system", IEEE Trans. Ind. Electron., vol. 61, no. 8, pp. 4022-4031, Aug. 2014.

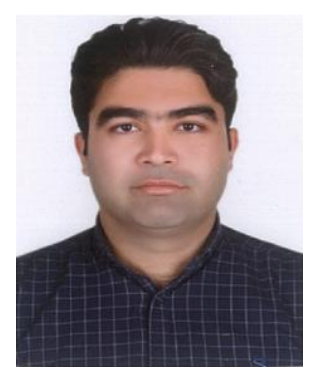

Hamed Bizhani (S'17) was born in Mashhad, Iran, in 1988. He received the B.Sc. degree from Birjand University, Birjand, Iran, in 2011, and M.Sc. degrees from K. N. Toosi University of Technology, Tehran, Iran, in 2013, both in electrical engineering. He is currently working toward the Ph.D. degree in electrical engineering with University of Zanjan, Zanjan, Iran. He is a Visiting Research Associate at Curtin University, Perth, Australia. His current research interests include multiport power electronic converters, control and integration of distributed generations, space vector modulation, and hybrid electric vehicle.

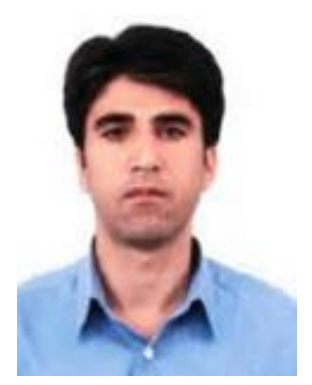

Reza Noroozian (M'09) was born in Iran. He received the B.Sc. degree from University of Tabriz, Tabriz, Iran, in 2000, and the M.Sc. and Ph.D degrees in electrical engineering from Amirkabir University of Technology, Tehran, Iran, in 2003 and 2008, respectively. He is a Professor with the Department of Power Engineering at the University of Zanjan, Zanjan, Iran. His areas of interest include power electronics, power systems, power quality, integration and control of renewable generation units, custom power, micro grid operation, distributed-generation modeling, as well as operation and interface control.

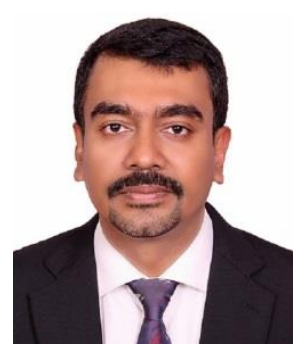

Dr. S. M. Muyeen (S'03-M'08SM'12) received his B.Sc. Eng. Degree from Rajshahi University of Engineering and Technology (RUET), Bangladesh formerly known as Rajshahi Institute of Technology, in 2000 and M. Eng. and Ph.D. Degrees from Kitami Institute of Technology, Japan, in 2005 and 2008, respectively, all in Electrical and Electronic Engineering. At the present, he is working as an Associate Professor in the Department of Electrical and Computer Engineering at Curtin University, Perth, Australia. His research interests are power system stability and control, electrical machine, FACTS, energy storage system (ESS), Renewable Energy, and HVDC system. He has been a Keynote Speaker and an Invited Speaker at many international conferences, workshops, and universities. He has published more than 175 articles in different journals and international conferences. He has published six books as an author or editor. $\mathrm{He}$ is serving as Editor/Associate Editor for many prestigious Journals from IEEE, IET, and other publishers including IEEE Transactions of Sustainable Energy, IEEE Power Engineering Letters, IET Renewable Power Generation and IET Generation, Transmission \& Distribution, etc. Dr. Muyeen is the senior member of IEEE and Fellow of Engineers Australia.

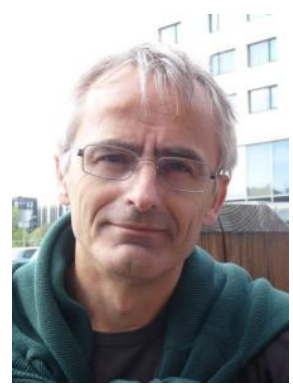

Frede Blaabjerg (S'86-M'88-SM'97F'03) was with ABB-Scandia, Randers, Denmark, from 1987 to 1988. From 1988 to 1992, he got the $\mathrm{PhD}$ degree in Electrical Engineering at Aalborg University in 1995. He became an Assistant Professor in 1992, an Associate Professor in 1996, and a Full Professor of power electronics and drives in 1998. From 2017 he became a Villum Investigator. $\mathrm{He}$ is honoris causa at University Politehnica Timisoara (UPT), Romania and Tallinn Technical University (TTU) in Estonia. His current research interests include power electronics and its applications such as in wind turbines, PV systems, reliability, harmonics and adjustable speed drives. He has published more than 500 journal papers in the fields of power electronics and its applications. He is the co-author of two monographs and editor of 7 books in power electronics and its applications. He has received 26 IEEE Prize Paper Awards, the IEEE PELS Distinguished Service Award in 2009, the EPEPEMC Council Award in 2010, the IEEE William E. Newell Power Electronics Award 2014 and the Villum Kann Rasmussen Research Award 2014. He was the Editor-in-Chief of the IEEE TRANSACTIONS ON POWER ELECTRONICS from 2006 to 2012. He has been Distinguished Lecturer for the IEEE Power Electronics Society from 2005 to 2007 and for the IEEE Industry Applications Society from 2010 to 2011 as well as 2017 to 2018. In 2018 he is President Elect of IEEE Power Electronics Society. He is nominated in 2014, 2015, 2016 and 2017 by Thomson Reuters to be between the most 250 cited researchers in Engineering in the world. 